\title{
Bonding of adhesives to Er:YAG laser-treated dentin
}

\author{
Eugenia Koliniotou-Koumpia' \\ Pantelis Kouros ${ }^{1}$ \\ Lazaros Zafiriadis ${ }^{1}$ \\ Effimia Koumpia ${ }^{2}$ \\ Pavlos Dionysopoulos' \\ Vassilis Karagiannis ${ }^{3}$
}

\section{ABSTRACT}

Objective: The shear bond strength of adhesives applied to dentin was investigated after irradiation with an erbium-doped yttrium aluminum garnet (Er:YAG) laser.

Methods: Superficial and deep dentin specimens from human molars were treated either with carbide bur or an Er:YAG laser. Two etch and rinse adhesives (Single Bond and XP Bond) and two self-etch adhesives (Prompt L-Pop and Xeno III) were employed to bond the composite. Shear bond strength (SBS) was determined after storage in water for $24 \mathrm{~h}$ using a universal testing machine with a crosshead speed of $0.5 \mathrm{~mm} / \mathrm{min}$. Failure patterns and modes were analyzed and evaluated using a stereomicroscope. In addition, samples were processed for Scanning Electron Microscopy SEM evaluation. A linear mixed model was used, and pairwise comparisons were made using the Bonferroni test.

Results: Results showed significant differences between the levels of dentin treatment $(p=.01)$ in carbide bur-cut dentin and lased dentin, as well as significant interaction effects due to the depth of dentin and the bonding system used. The etch and rinse adhesives bonded less effectively with lased dentin than with carbide bur-cut dentin, while self-etch adhesives bonded equally well with lased and bur-cut superficial dentin but much less effectively with lased deep dentin than with bur-cut deep dentin. SEM revealed a predominantly adhesive failure mode in laser-ablated fractured specimens, while a mixed failure mode was apparent in the bur-cut fractured specimens.

Conclusions: Cavities prepared by laser seem less receptive to adhesive procedures than conventional bur-cut cavities. (Eur J Dent 2012;6:16-23)

Keywords: Laser irradiation, Er: YAG laser, shear bond strength, self-etch adhesives, etch and rinse adhesives.

1 Department of Operative Dentistry, Aristotle University of Thessaloniki, Greece

2 Department of Orthodontics, Aristotle University of Thessaloniki, Greece.

3 Department of Fundamental Dental Science Aristotle University of Thessaloniki, Greece.

- Corresponding author: Dr. Eugenia Koliniotou-Koumpia Department of Operative Dentistry, Dental School, Aristotle University of Thessaloniki, 54124 Thessaloniki, GREECE

Tel. +302310342957 Fax. +302310344802

e-mail: jenydadent.auth.gr

\section{INTRODUCTION}

Tooth cavities are commonly prepared by means of rotary instruments equipped with either diamond or tungsten carbide burs. Recently, the use of laser technology has been introduced as an alternative to traditional mechanical rotating instruments in cavity preparation. ${ }^{1}$ The Er:YAG laser in particular, with its ultra-short square-pulse technology (wavelength $2.94 \mu \mathrm{m}$ ), has been used clinically and is particularly popular for removing 
caries and preparing micro-cavities, with a view toward 'minimally invasive dentistry ${ }^{2}$ or 'minimal intervention dentistry. ${ }^{3}$ Many characteristics of lased dentinal tissue have been mentioned in the literature as being advantageous for resin bonding. Laser irradiation leads to the formation of a microscopically rough dentin surface with a micro-retentive pattern that reveals tubule openings without a smear layer. .-7 $^{-}$This characteristic is supposed to favor the bond strength of resin-based materials with dentin. 8,9 With new self-etching adhesive systems, the dentinal smear layer is no longer completely eliminated but is treated like a substrate. The immediate adhesion values obtained with these new biomaterials on irradiated dentin surfaces are widely studied. ${ }^{10-12}$ The primary objective of this study was investigating the application of self-etching adhesive (XENO III) on lased dentin. Reports of bond strengths for Er:YAG lased tooth substrates reported in the literature have been confusing and even contradictory. ${ }^{9-12}$ One study reports higher bond strengths in laser-conditioned as opposed to acid-etched dentin. ${ }^{9}$ Others report significantly lower bond strengths, ${ }^{12-15}$ while no significant differences were found in additional reports. ${ }^{11,16,17}$ Other authors also mention laser damage to enamel and dentin because fractures that are more cohesive occur in dentin. ${ }^{18-21}$ Moreover, this laser irradiation-induced structural weakening is not only confined to the uppermost layer of dentin but modifies and weakens dentin over a thickness of 3-5 $\mu \mathrm{m}$, which understandably jeopardizes adhesion of composite material. ${ }^{22}$

The aim of this study was to investigate the effect of Er:YAG laser irradiation on the shear bond strength of four contemporary adhesives (etch and rinse \& self-etch) used on superficial and deeplased dentin. The null hypotheses tested were: (a) that Er:YAG lasers and carbide burs are equally effective in terms of shear bond strength and (b) that there is no difference between traditional acid-etch or self-etch procedures with regards to the shear bond strength in lased dentin.

\section{MATERIALS AND METHODS}

Twenty-four non-carious human third molars were stored in $0.5 \%$ chloramine solution at $4^{\circ} \mathrm{C}$ for use in this study. The roots of the teeth were removed $2 \mathrm{~mm}$ below the cementoenamel junction with a water-cooled diamond saw, and their crowns were bisected longitudinally in a mesiodistal direction at low speed using a sectioning machine IIsomet 1000; Buehler Ltd, Lake Bluff, Il, USA), providing a total 48 buccal and lingual halves of teeth.

These halves of teeth were first sectioned below the dentino-enamel junction to expose the most superficial dentin (SD) and were then sectioned again at $2.0 \pm 0.1 \mathrm{~mm}$ deep to expose deep dentin (DD). In this way, the same tooth provided both SD and DD surface areas for adhesion; these surfaces were delimited with the aid of teflon tape with silicone adhesive (PTFE teflon tape, CS Hyde Company, Inc. Illinois, USA), and $3 \mathrm{~mm}$ diameter holes were provided by means of a modified rubber-dam punch. This step was necessary to ensure that the adhesive bonding system and the composite resin restorative material were inserted in a defined surface area that was never larger than the one being tested.

Dentin surface specimens were randomly divided into two groups that were conditioned either with an Er:YAG laser machine lexperimental group) or with a carbide bur (control group). Superficial and deep dentin surfaces were randomly distributed into eight experimental sub-groups.

For the carbide bur-cut specimens, teeth were mounted in a chuck, and a smear layer was created by removing a thin layer of the surface receiving high speed rotary preparation with a \#57 straight fissure tungsten carbide bur (Brasseler USA, Savannah, GAl at approximately 200,000 rpm with air/water coolant. The laser-treated surfaces were uniformly irradiated under continuous water-cooling using a commercially available Er:YAG laser (DEKAsmart 2940d+, Calenzano, Firenze, Italyl at $17 \mathrm{~mm}$ focal distance. Settings for dentin ablation were $10 \mathrm{~Hz}$ of frequency, $80 \mathrm{~mJ}$ of energy and short-pulse mode (pulse length $230 \mu \mathrm{s}$ ). The dentin samples were embedded in self-cure resin (Concise 3M Dental Products, St Paul, MN, USA) in the middle of a metal ring mold. Two etch and rinse adhesives [Single Bond (SB) and XP Bond (XPB)] were applied with acid etching, and two self-etch adhesives [Prompt L-Pop (PLP) and Xeno III (X III)] were employed to bond the composite. Materials were chosen to test the "etch and rinse" and the "self-etch" approaches of two different manufacturers. Single Bond and Prompt-L-Pop were produced by 3 M-ESPE and are water based ad- 
hesives, while ethanol based XP Bond and water/ ethanol based Xeno III were produced by Dentsply. The materials used and their chemical compositions are listed in Table 1.

Surfaces were identified to avoid buccal and lingual halves of one tooth being assigned to the same experimental group. The same tooth was treated buccally with etch and rinse and lingually with self-etch adhesives. Six dentin samples were treated for each adhesive bonding system. Subsequently, the adhesives were applied on the surfaces strictly following the manufacturers' instructions. For the "etch and rinse" adhesive systems (SB, XPB), the dentin surface was etched with $35 \%$ phosphoric acid for the $15 \mathrm{sec}$, (3M ESPE, $\mathrm{GmbH}$, Germany), thoroughly rinsed and lightly blot-dried, leaving the dentin visibly moist. Adhesive resin was then applied to etched dentin according to the manufacture recommendations and light-cured prior to composite resin application. The "self-etch" adhesive systems (PLP, X III) were brushed onto the dentin surface, gently air-blotted and light-cured according to the manufacture instructions prior to composite resin application. After curing the adhesives, a teflon mold $3 \mathrm{~mm}$ in diameter and $4 \mathrm{~mm}$ in height was placed over the ring with the dentin sample and filled with Filtek Supreme composite resin (3M ESPE, GmbH, Germanyl in two increments. Each increment was light-cured according to manufacture recommendations using a Bluephase (Ivoclar Vivadent AG, Schaan, Liechtenstein) device with a light output of not less than $550 \mathrm{~mW} \mathrm{~cm}$. The intensity of the light curing unit was measured using a Bluephase meter (Ivoclar Vivadent AG, Schaan, Liechtenstein). This procedure resulted in cylindrical specimens of composite resin measuring $3 \mathrm{~mm}$ in diameter and $4 \mathrm{~mm}$ in height being bonded to the dentin.

The shear bond strength (SBS) was determined after storage for $24 \mathrm{~h}$ in water. Shear testing was conducted by means of an Instron-like machine (AMETEC Accu Force III 500 Mansfield and Green Division) at a crosshead speed of $0.5 \mathrm{~mm} / \mathrm{min}$. The force $(N)$ at failure was recorded and the shear bond strength values ( $\mathrm{MPa}$ ) were calculated from the peak load at failure divided by the specimen surface area.

Data (the mean bond strengths (MPa) of each specimen) were submitted to a linear mixed model with treatment (carbide bur or Er:YAG laser), depth of dentin (superficial dentin or deep dentin) and adhesive bonding system (total-etch or selfetch) as fixed factors and material (single Bond, XP Bond, Prompt L-Pop or Xeno III) as a random factor. ${ }^{21}$ The normality assumption was tested with the Shapiro Wilk test and the Intraclass Correlation Coefficient (ICC) concerning the levels of the random factor was also computed. Pairwise comparisons between groups were made with the Bonferroni correction of Type I Error. All tests were performed with SPSS 15.0 and the level of significance was set at $P<.05$.

Failure patterns at the dentin/restorative material interface were analyzed under a stereomicroscope at $40 \mathrm{x}$ magnification (Olympus Co, Tokyo, Japan) for determination of the failure modes. Failure was considered ${ }^{14,24}$ to be al adhesive if it occurred at the dentin/adhesive interface, b) cohesive if it occurred in the material or in the substrate and c) mixed when involving both the interface and the material. The bond failure sites were not statistically analyzed. Two specimens of each fracture failure mode from the 16 groups tested for shear bond strength were randomly selected for SEM evaluation. The specimens were mounted on stubs, sputter-coated with carbon and examined by one evaluator under SEM (Jeol, J.S.M.-840 Tokyo, Japan) at $19 \mathrm{KV}$.

\section{RESULTS}

No significant differences were observed between the levels of the random factor material $(P=.659$, Single Bond $=16.2 \pm 6.7$, XP Bond $=15.9 \pm 5.4$, Prompt-L-Pop $=17.4 \pm 4.8$, Xeno $\| I=19.6 \pm 4.8$, variance estimate $=0.6, \mathrm{ICC}=4 \%$ ).

Dentinal surfaces treated with the Er:YAG laser displayed smaller adhesive values in almost each combination of the adhesive system and dentin depths ( Figure 1).

There was a significant difference between the levels of dentin treatment $(P<.001)$ and carbide bur-cut dentin (20.2 \pm 4.5 , lased dentin 14.4 \pm 4.4 ) and a significant interaction effect between the depth of dentin, treatment and the adhesive bonding system $(P=.004)$.

Bonferroni pairwise comparisons concerning the interaction effect gave the following results:

1) In deep dentin, there was a significant difference between lased (13.7 \pm 2.97$)$ and carbide burcut dentin $(17.3 \pm 3.8)$ in shear bond strength val- 
ues when total-etch adhesives were used $(P=.033)$ and between lased $(15.4 \pm 2.4)$ and carbide bur-cut (21.5 \pm 3.8$)$ dentin when adhesive bonding systems were self-etch ones $(P<.001)$.

2) In superficial dentin, there was a significant difference between lased (11.3 \pm 2.92$)$ and carbide bur-cut dentin (21.89 \pm 5.3$)$ in shear bond strength values when total-etch adhesives were used $(P<$.001). When self-etch adhesives were used, the values were statistically similar for both lased (16.97 \pm 6.3 ) and carbide bur-cut dentin $(20.05 \pm 3.9)$ $(\mathrm{P}=.067)$ ( Figure 1).

Pairwise comparison tests also revealed that when carbide bur was used in SD, total-etch adhesives yielded shear bond values $(21.89 \pm 5.3)$ that were significantly higher than those achieved in DD (17.3 \pm 3.8$)(P=.007)$ (Figure 2).

There was a significant difference between totaletch (17.3 \pm 3.8$)$ and self-etch $(21.5 \pm 3.8)$ adhesives when the depth of the dentin specimen was deep

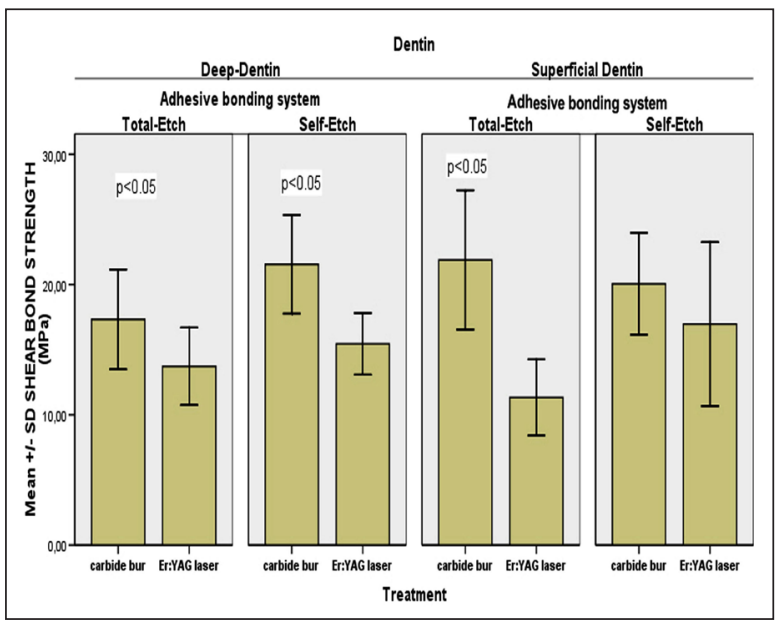

Figure 1. Adhesive values of the adhesive bonding system: pairwise comparisons between carbide bur-cut and laser ablation treatment.

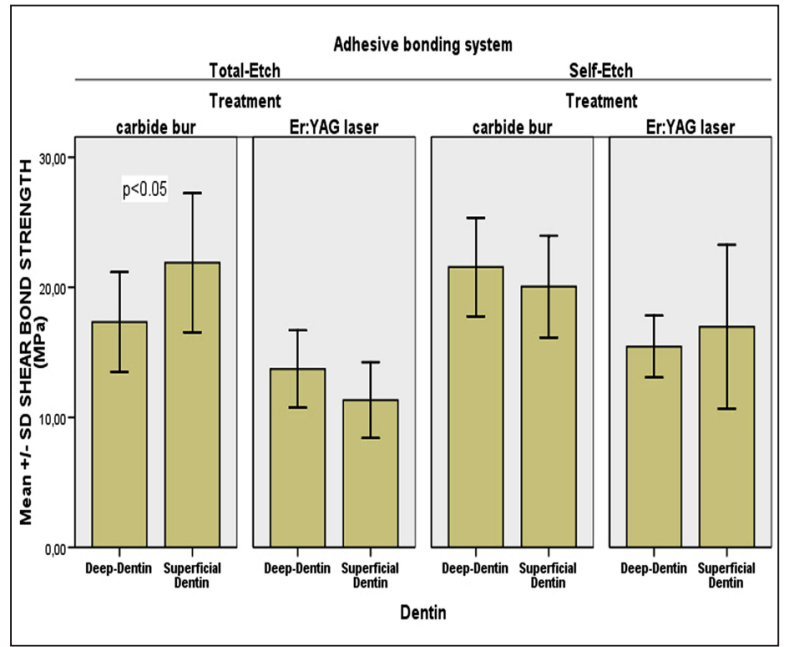

Figure 2. Adhesive values of the adhesive bonding system: pairwise comparisons between deep dentin and superficial dentin. dentin and the treatment was with bur-cut ( $P=$ =037); there was also a significant difference between total-etch (11.3 \pm 2.92$)$ and self-etch (16.97 \pm 6.3 ) adhesives when the dentin was superficial and the treatment was laser-ablation ( $P=.008$ ) (Figure 3).

A mixed failure mode was predominantly observed in fractured specimens that were carbide bur-cut. (Figure 4b). A minimum cohesive failure mode was observed in SD-fractured specimens, (Figure 5b) while some adhesive failure mode was observed, especially in DD- fractured specimens. The groups treated with the Er:YAG laser exhibited (Figure 6b). a higher percentage of adhesive fracture regardless of the depth of dentin. (Figure $5 \mathrm{a}$, $6 a, 6 b)$. It was even possible to observe very different zones of failure on the same surface. (Figure $4 a)$.

\section{DISCUSSION}

The results obtained from this study demand rejection of the first null hypothesis that Er:YAG laser or carbide bur treatment is equally effective in terms of SBS on dentin; that is, specimens bonded on lased dentin showed significantly lower SBS.

Many factors can influence the bonding performance of adhesive systems to dentin including dentin substrate, dentin treatment and dentin conditioning. ${ }^{25,26}$

Preparation of dental substrates with rotary instruments leaves a smear layer on the surface. The low surface energy of this layer hinders impregnation of the dentin with the adhesive agent and thus prevents adequate adhesion. This problem has been solved by applying acid-etching or self-etching to dentin. ${ }^{27}$

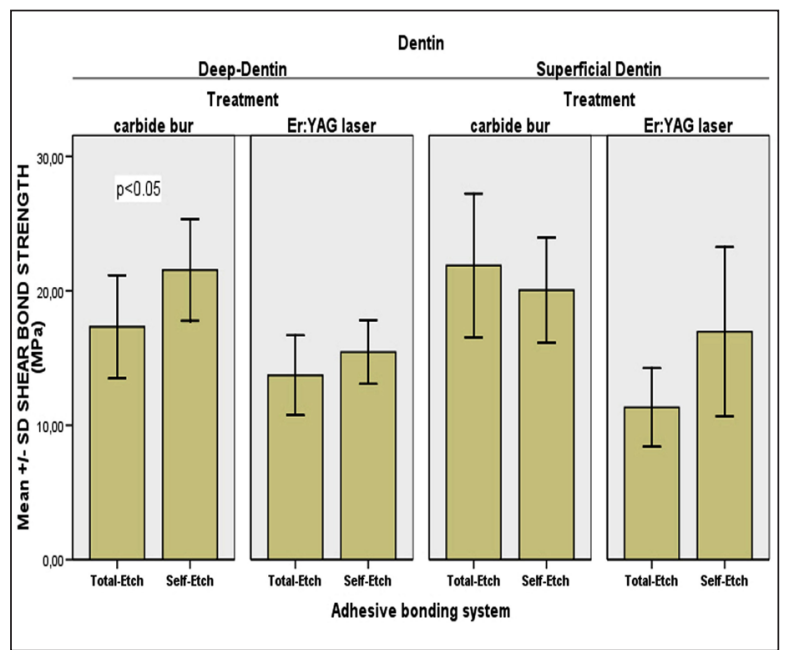

Figure 3. Adhesive values of the adhesive bonding system: pairwise comparisons between total-etch and self-etch adhesive systems. 
Recent research ${ }^{20}$ has described the concept of utilizing the smear layer as a bonding substrate but with improved formulation that can etch beyond the smear layer into the underlying dentin

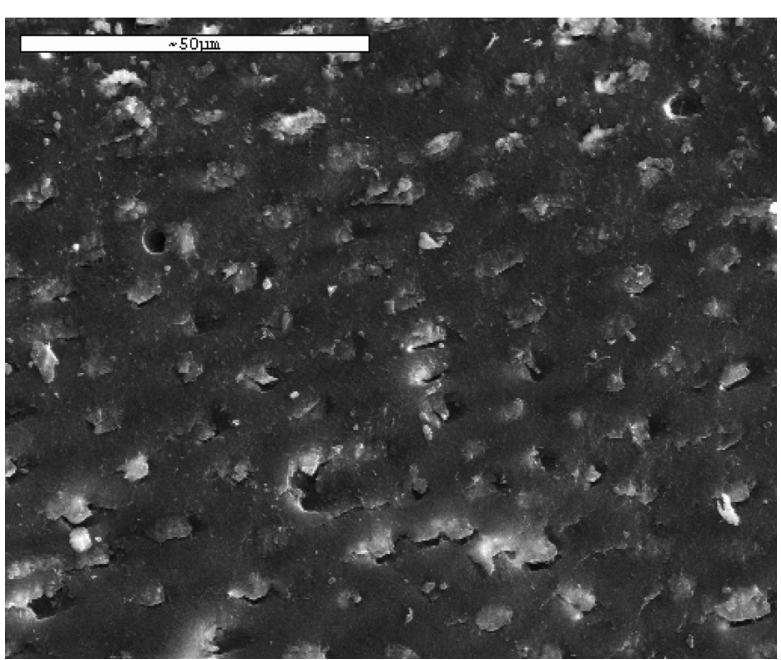

Figure 4a. SEM micrograph of the debonded dentin specimen from XP Bond

(total-etch adhesive) and laser-treated superficial dentin. The interface failed to be uniformly adhesive within dentin. In addition, many micro-cracks can be observed.

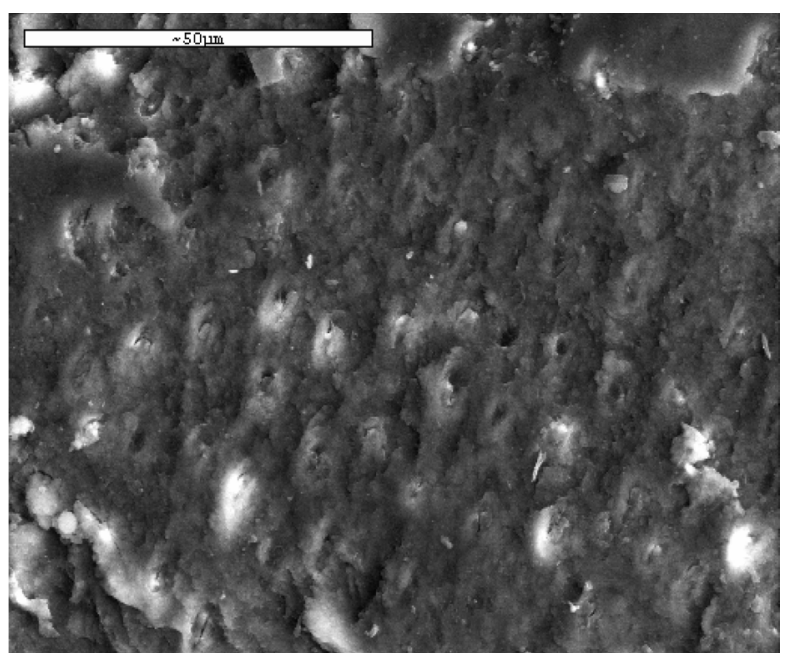

Figure 5a. SEM micrographs of the debonded dentin specimen from Xenon III Iselfetch adhesive) and laser-treated superficial dentin. Adhesive failure was observed.
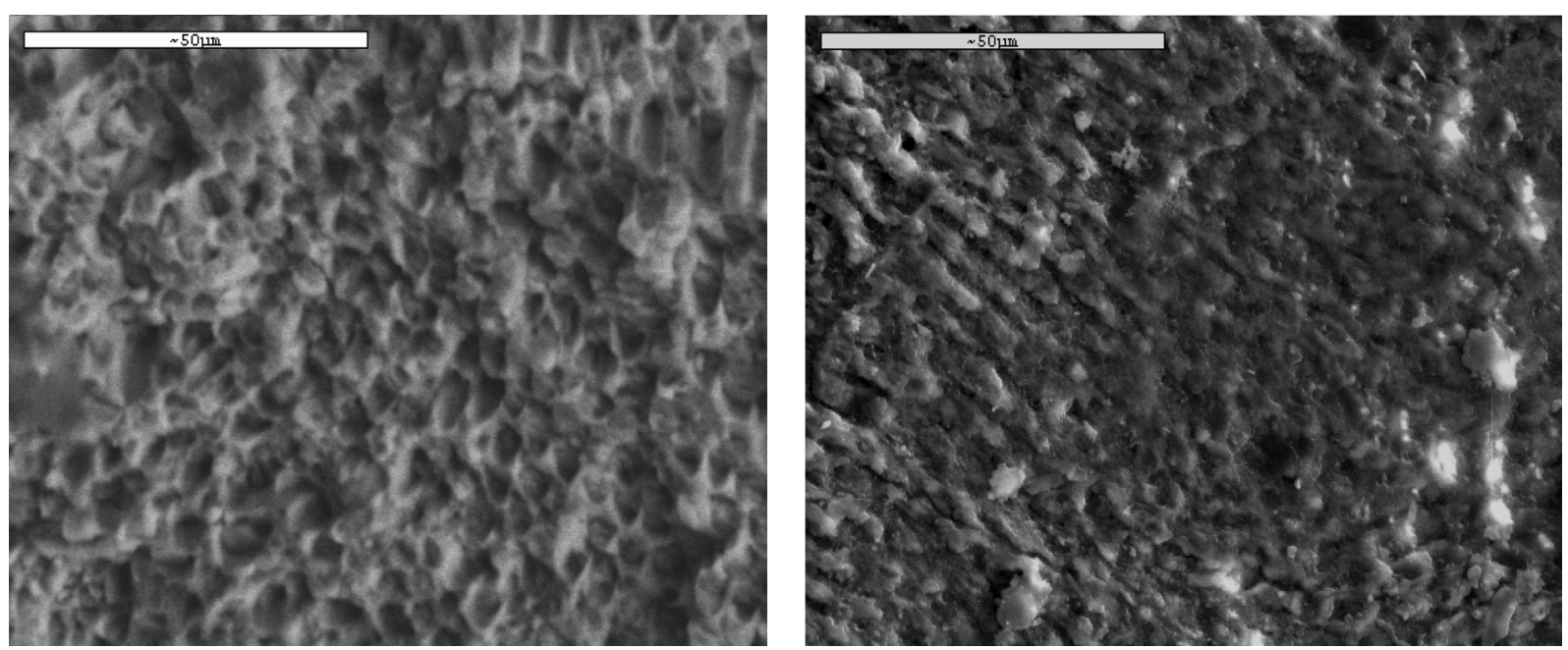

Figure 6. SEM micrographs of the debonded dentin specimen from Prompt L-Pop (self-etch adhesive) and laser-treated (a) superficial or (b) deep dentin.

matrix. An alternative technique that could produce better effects than acids for substrate surface treatment has been highlighted in relation to the role of the Er:YAG laser.

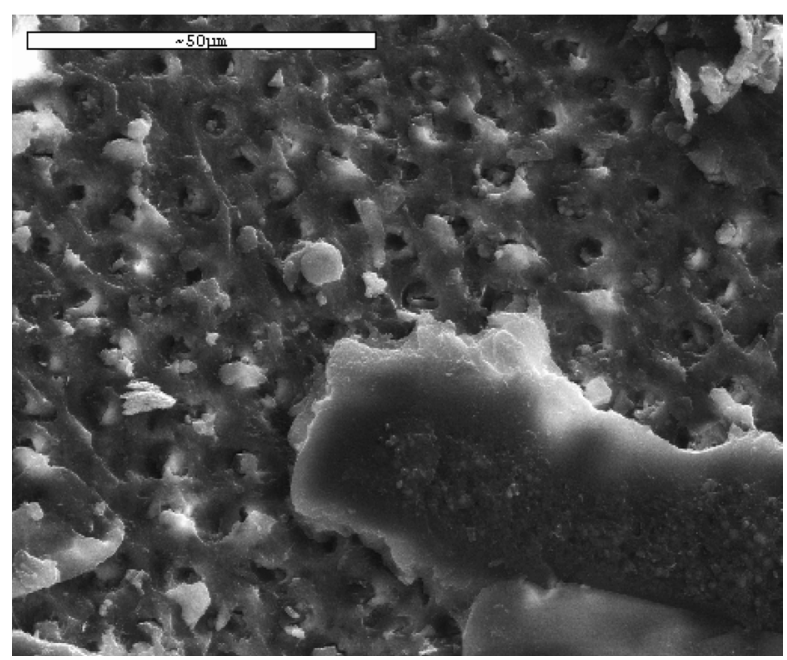

Figure 4b. SEM micrograph of the debonded dentin specimen from XP Bond and carbide-treated superficial dentin. A mixed failure mode was observed.

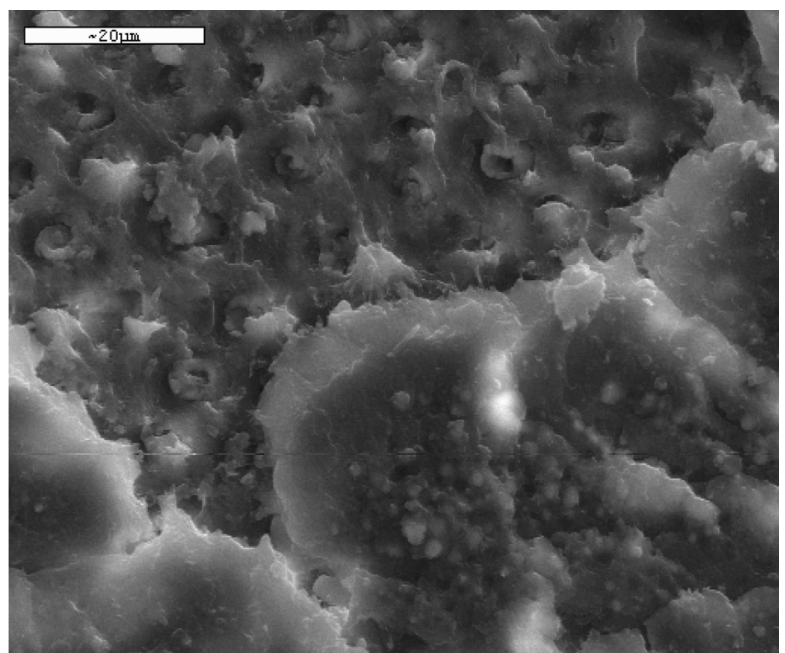

Figure $5 \mathrm{~b}$. SEM micrograph of the debonded dentin specimen from Xenon III- and

European Journal of Dentistry 
Previous reports have claimed that there are certain advantages in bonding to lased dentin because of an apparently enlarged surface area for adhesion based on the scaly and flaky surface appearance following Er:YAG irradiation. 5,9,28

The results in this study demonstrate that dentinal surfaces treated by the Er:YAG laser displayed smaller adhesive values than those treated with a carbide bur, regardless of the adhesive system at both dentin depths and the interaction effect between depth of dentin, treatment and the adhesive bonding system. The results of this study agree with similar reported results $15,18,20,22,29$ in which the bond strength of different adhesive systems applied to laser-treated dentin was tested until failure, in micro-tensile or shear, and the interfacial morphology was observed under SEM. In contrast with our results, some investigators ${ }^{30}$ reported that there was no difference in the bonding to either carbide bur-treated or laser-treated dentin. It has also been postulated ${ }^{9,28}$ that lased dentin surfaces are at an advantage because of an apparently enlarged surface area for adhesion based on the scaly and flaky surface that appears following Er:YAG irradiation.

Li et $\mathrm{al}^{{ }^{31}}$ have suggested that the Er:YAG laser thermo-mechanically ablates hard tissues by causing micro-explosions within inorganic structures in teeth. Initially, the Er:YAG laser vaporizes water and other hydrated organic components until internal pressure causes the destructive explosion of the inorganic component before the melting point is reached. ${ }^{31}$ It has been proposed ${ }^{22}$ that there is a fusion of collagen fibrils caused by the ablation of dentin. This will lead to a lack of interfibrillar space, restricting resin diffusion to within the subsurface intertubular dentin. The lack of resin penetration in laser-ablated dentin is the most likely explanation for lower bond strengths. ${ }^{22}$

The results indicated that SD carbide bur cut specimens conditioned with total-etch adhesives presented a higher bond strength value than the DD carbide bur cut specimens. This result could be explained by the fact that in DD (closer to the pulp), the tooth tissue is less mineralized and presents a smaller amount of collagen ${ }^{32}$ with wider tubules, 33,34 thus increasing the difficulties for the adhesive material. ${ }^{35}$

There was no statistically significant difference in the SBS for the SD- and DD-lased specimens. When Er:YAG laser irradiation treatment was used, a substantial decrease in shear bond strength was observed when compared to the carbide bur cut values.

The adjunctive use of phosphoric acid followed by water rinsing appeared to eliminate the surface laser-modified layer. ${ }^{22}$ The results of this study require, in part, the rejection of the second null hypothesis, which states that there is no difference in the shear bond strength between traditional acidetch or self-etch procedures on lased dentin.

There was also a significant difference between total-etch and self-etch adhesives when the dentin was superficial and treatment was performed with laser ablation (Figure 3). The absence of smear layer formation during the preparation of the superficial dentin by the Er:YAG laser may explain the improved adhesion values of self-etching adhesive systems. ${ }^{9}$ Also, the lack of resin penetration in laser-ablated dentin is most likely the explanation for lower bond strength with etch and rinse adhesives. ${ }^{22}$ Self etch adhesives used in this study were of aggressive nature, $\mathrm{pH}<1$. Self etching in carbide bur cut specimens only dissolves

Table 1. Chemical composition of adhesives tested.

\begin{tabular}{|c|c|c|c|}
\hline Materials & & Composition & Manufacturer \\
\hline \multirow[b]{2}{*}{ Total-Etch } & Single Bond & $\begin{array}{c}\text { Bis-GMA, HEMA, dimethacrylate, functional copolymer } \\
\text { ethanol, water, silica fillers }\end{array}$ & 3M ESPE, Seefeld, Germany \\
\hline & XP Bond & $\begin{array}{l}\text { Carboxylic acid modified dimethacrylate (TCB resin), } \\
\text { PENTA, UDMA, TEGDMA, HEMA, Butylated benzenediol } \\
\text { (stabilizer), ethyl-4-dimethylaminobenzoate, camphorqui- } \\
\text { none, functionlized amorphous silica, t-butanol }\end{array}$ & DENTSPLY De Trey GmbH Constanz Germany \\
\hline \multirow[b]{2}{*}{ Self-Etch } & Prompt L-Pop & $\begin{array}{c}\text { Methacrylated phosphoric esters, Bis-GMA, CQ, initiator, } \\
\text { stabilizer, 2-HEMA, polyalkenoic acid, water }\end{array}$ & 3M ESPE, Seefeld, Germany \\
\hline & Xeno III & $\begin{array}{l}\text { Liquid A:HEMA Purified water, Ethanol, BHT, Highly dis- } \\
\text { persed silicon dioxide Liquid B: Phosphoric acid modified } \\
\text { methacrylate (Pyro-EMA), Mono fluoro phosphazene modi- } \\
\text { fied methacrylate (PEM-F), Urethane dimethacrylate, BHT, } \\
\text { camphorquinone, Ethyl-4-dimethylamini benzonate }\end{array}$ & DENTSPLY De Trey GmbH Constanz Germany \\
\hline
\end{tabular}


the smear layer, but does not remove the dissolved calcium phosphates, as there is no rinse phase. Resin-encapsulated calcium phosphates within the exposed collagen mesh are rather soluble and may explain the lower bonding performance of strong self-etch adhesives.

\section{CONCLUSIONS}

It can be concluded that: al specimens prepared by laser ablation appear less receptive to adhesive procedures than conventional carbide bur cut specimens, and b) Er:YAG laser-treated dentinal surfaces displayed smaller adhesive values irrespective of the adhesive system (totaletch vs. self-etch) at both dentin depths, and c) self-etch adhesives appear to interact better with Er:YAG laser-treated dentinal surfaces provide higher adhesion values.

\section{ACKNOWLEDGMENTS}

The kind help from the Physics Department, Scanning Electron Microscopy, Aristotle University of Thessaloniki, Greece and from Associate Professor Pavlidou Eleni in performing SEM procedures for this present work is very much appreciated.

\section{REFERENCES}

1. Hibst R, Keller U, Stainer R. The effect of pulsed Er:Yag laser radiation on dental hard tissues. Laser Med Surg 1988;4:163-165.

2. Degrange $H$, Roulet JF. Minimally invasive Dentistry with Bonding. J Am Dent Assoc 1998;129:484-485.

3. Tyas MJ, Anusavice KJ, Frencen JE. Minimal intervention dentistry-a review. Int Dent J 2000;50:1-12.

4. Armengol V, Jean A, Rohanizaden R, Hamel H. Scanning electron microscopic analysis of diseased and healthy dental hard tissues after Er: YAG laser irradiation: in vitro study. J Endod 1999;25:543-546.

5. Keller U, Hibst R. Experimental studies of the application of the Er: YAG laser on dental hard substances II. Light microscopic and SEM investigations. Laser in Surgery and Medicine 1989;9:345-351.

6. Niu W, Norico Eto J, Kimura Y, Hirono Takeda F, Matsumoto K. A study on microleakage after resin filling of class V cavities prepared by Er:YAG laser. J Clin Laser Med Surg 1998;16:227-231.

7. Souza-Zaroni WC, Chinellati MA, Delfino CS, Pécora JD, Palma-Dibb RG,Corona SA. Adhesion of a self-etching system to dental substrate prepared by Er:YAG laser or air abrasion. J Biomed Mater Res B Appl Biomater 2008;86B:321-329.
8. Gonclaves M, Corona SA, Borsatto MC, Silva PC, Pécora JD. Tensile bond strength of dentin-resinous system interfaces conditioned with Er:YAG laser irradiation. J Clin Laser Med Surg 2002;20:89-93.

9. Visuri S, Gilbert J, Wright D, Wigdor H, Walsh JJ. Shear strength of composite bonded to Er:YAG laser-prepared dentin. J Dent Res 1996;75:599-605.

10. Brulat N, Rocca JP, Leforestier E, Fiorucci G, Nammour S, Bertrand MF. Shear bond strength of self-etching adhesive systems to Er:YAG-laser- prepared dentin. Lasers Med Sci 2009;24:53-57.

11. Esteves-Oliviera M, Zezell DM, Apel C, Turbino ML, Aranha AC, Eduardo Cde, Gutknecht N.Bond strength of self-etching primer to bur cut, Er,Cr:YSGG, and Er:YAG lased dental surfaces. Photomed Laser Surg 2007;25:373-380.

12. Ramos AC, Esteves-Oliviera M, Arana-Chavez VE, de Paula Eduardo C. Adhesives bonded to erbium:yttrium-aluminum-garnet laser-irradiated dentin: transmission electron microscopy, scanning electron microscopy and tensile bond strength analyses. Lasers Med Sci 2010;25:181-189.

13. Attrill DC, Farrar SR, King TA, Dickinson MR, Davies RM, Blinkhon AS. Er:YAG $(\lambda=2.94 \mu \mathrm{m})$ laser etching of dental enamel as an alternative to acid etching. Lasers Med Sci 2000;15:154-161.

14. Gonçalves M, Corona SA, Palma Dibb RG, Pécora JD. Influence of pulse repetition rate of Er:YAG laser and dentin depth on tensile bond strength of dentin-resin interface. J Biomed Mater Res A 2008;86:477-482.

15. Kameyama A, Kawada E, Takizawa M, Oda Y, Hirai Y. Influence of different acid conditioners on the tensile bond strength of 4-META/MMA-TBB resin to Er:YAG laser irradiation bovine dentin. J Adhesive Dent 2000;2:297-304.

16. Armengol V, Jean A, Weiss P, Hamel H. Comparative in vitro study of the bond strength of composite to enamel and dentine obtained with laser irradiation of acid-etch. Lasers Med Sci 1999;14:207-215.

17. Kataumi M, Nakajima M, Yamada T, Tagami J. Tensile bond strength and SEM evaluation of Er:YAG laser irradiated dentin using dentin adhesive. Dent Mater J 1998;17:125138.

18. De Munck J, Van Meerbeek B, Yudhira R, Lambrechts P, Vanherle $G$. Micro-tensile bond strength of two adhesives to Erbium:YAG-lased vs bur-cut enamel and dentin. Eur $J$ Oral Sci 2002;110:322-329.

19. Giachetti L, Russo D, Scarpelli F, Vitale M. SEM analysis of dentin treated with the Er:YAG laser: a pilot study of consequences resulting from laser use on adhesion mechanisms. J Clin Laser Med Surg 2004;22:35-41. 
20. Martinez-Insua A, Da Silva D, Rivera F, Santana-Penin $U$. Differences in bonding to acid-etched or Er:YAG-laser-treated enamel and dentin surface. J Prosthet Dent 2000;84:280-288.

21. Van Meerbeek B, De Munck J, Mattar D, Van Landuyt K, Lambrechts P. Microtensile bond strengths of an etch\&rinse and self-etch adhesive to enamel and dentin as a function of surface treatment. Oper Dent 2003;28:647660.

22. Ceballos L, Toledano M, Osorio R, Tay F, Marshall G. Bonding to Er-YAG-laser-treated dentin. J Dent Res 2002;81:119122.

23. Norusis M. SPPS 15.0 Advanced Procedures Companion, Prentice Hall, New York 2007.

24. Versluis A, Tantbirojn D, Douglas WH. Why do shear bond tests pull out dentin? J Dent Res 1997;76:1298-1307.

25. Braga RR, Meira JB, Boaro LC, Xavier TA Adhesion to tooth structure: A critical review of "macro" test methods. Dent Mater 2010;26:e38-49.

26. Armstrong S, Geraldeli S, Maia R, Raposo LH, Soares CJ, Yamagawa J. Adhesion to tooth structure: A critical review of "micro" bond strength test methods. Dent Mater 2010;26:e50-62.

27. Fusayama T. Total etch technique and cavity isolation. $J$ Esthet Dent 1992;4:105-109.

28. Stiesch-Scholz M, Hanning M. In vitro study of enamel and dentin marginal integrity of composite and compomer restorations placed in primary teeth after diamond or Er: YAG laser cavity preparation. J Adhes Dent 2000;2:213-222.

29. Dunn WJ, Davis JT, Bush AC. Shear bond strength and SEM evaluation of composite bonded to Er:YAG laser-prepared dentin and enamel. Dent Mater 2005;21:616-624.

30. Çelik EU, Ergücü Z, Türkün LS, Türkün M. Shear bond strength of different adhesives to Er:YAG laser-prepared dentin. $J$ Adhes Dent 2006;8:319-325.

31. Li ZZ, Code JE, Van de Merwe WP. Er:YAG laser ablation of enamel and dentin of human teeth: determination of ablation rates at various fluences and pulse repetition rates. Laser Surg Med 1992;12:625-630.

32. Pashley DH. Dentin: A dynamic substrate-review. Scanning Microscopic 1989;3:161-176.

33. Swift Jr EJ, Perdigāo J, Heymann HO. Bonding to enamel and dentin:a brief history and state of the art. Quintessence Int 1995;26:95-110.

34. Pegato REF, Amaral FLB, Flório FM, Basting RT. Effect of different bonding strategies on adhesion to deep and superficial permanent dentin. Eur J Dent 2010;4:110-117.
35. De Souza AE, Corona SAM, Dibb RGP, Borsato MC, Pecora JD. Influence of Er:YAG laser on tensile bond strength of a self-etching system and a flowable resin in different dentin depths. J Dent 2004;32:269-275. 